\title{
Dental Marketing BMEG Approach (Build, Market, Expand and Grow Practice)
}

\author{
Roche Peñafuerte Ruiz* \\ KJR Dental Center Incorporated / Dental Marketing Philippines / Smile Line Philippines
}

*Corresponding author: Roche Peñafuerte Ruiz, Marketing Practitioner, Lecturer / Dental Marketing Lecturer, KJR Dental Center Incorporated, Las Piñas City, Philippines, Tel: +639088818809; E-mail: ehcor_r@yahoo.com

Received: 05 Apr, 2019 | Accepted: 13 May, 2019 | Published: 17 May, 2019

Citation: Ruiz RP (2019) Dental Marketing BMEG Approach (Build, Market, Expand and Grow Practice). Int J Dent Oral Health 5(3): dx.doi. org/10.16966/2378-7090.294

Copyright: (C) 2019 Ruiz RP. This is an open-access article distributed under the terms of the Creative Commons Attribution License, which permits unrestricted use, distribution, and reproduction in any medium, provided the original author and source are credited.

\begin{abstract}
Background: Dental Marketing has been in the International Convention since thirty-six (36) years ago. Dental Marketing is the process of understanding who your patient is, where they reside, and what they value. On the clinic perspective, patients must always be given an opportunity to have the best possible smile they deserve. It means you are providing the patient with an exceptional experience and with that they become a kind of an uncompensated evangelist - salesperson, for your practice.

Methods: Two (2) sets of questions with five (5) key points and an interval of six (6) months per dentist. One hundred fifty (150) dental clinics/ practitioners will be subjected to a two-page questionnaire with an identical perspective of marketing importance. The identification of whether what business type was also asked during the research. Out of the 150, second research was made using the same dental clinics/practitioners this time excluding the thirty (30) dental clinics/practitioners that were not interested.

Results: Dental Marketing is needed in the local settings and encourages participation from the dental practice circle. Dental Marketing provides an In-and-Out Approach to building and expanding dental practice. It is also identified that most of the participants were interested and only a few were not.

Conclusion: $92 \%$ of respondents said they need Marketing to build their practice and thought of it as an essential tool in their business. 9.2\% increase on the use of Digital Dental Marketing platform, and a $8 \%$ increase on a $\$ 1000$ (P50k) expenditures per month. Dental Marketing is and will always be part of the dental industry. In six (6) month time of the campaign, dental marketing has reflected good results in terms of an increase in patients turn-out.
\end{abstract}

\section{Introduction}

Dental Marketing is new but old; new because it was never actually mentioned in most of the dental seminars, lectures and other conventions around the country as the most obvious considerations is the fact that most of our dentists would like to know and be educated more on their discipline of dental practice or the so-called "Innovations" or dental practice specialization. It is old because due to the fact that in the United States, it is widely used and commonly considered before even starting their dental practice, it is always part and parcel of the strategies planning of dental practice. As a matter of fact, the marketing budget in acquiring patients is widely accepted [1].

In the USA, there are multiple companies offering different services for dental marketing - it is actually widely advertised. In the local setting, we don't have any (SEC - Securities and Exchange Commission) registered company that is mainly focused on the process of providing dental marketing campaign for the dental practitioners, maybe the fact that based on the random report from Philippine Dental Association.

\section{*PDA}

Philippine Dental Association last 2008-2010, there have been a $97: 3$ ratio in the percentage of a dental clinic as a $97 \%$ - "× Sole Proprietorship" and 3\% - registered as "* Corporation" [2].

Effective dental marketing will need lots and lots of effort. It takes diligence. Remember that the definition of marketing simply states that it is a process of identifying human needs and wants but marketing isn't a single event or a walk in the park "campaign," it's a system. To make sure that the machine and all of its mechanism works will requires that everybody within the company or clinic understand their role in marketing the clinic and practice in each and every patient interaction. Moreover, effective dental marketing involves a number of basic or fundamental steps. 
The clinic must start with a vision followed by their mission and complimenting it with how they want to be branded using "tag-lines" See my basic fundamentals below:

Be you and your brand: Branding is creating a statement about what you are - it's your practice title, your logo design, and also the message that these particular title or logo convey. For examples, T-shirt print, when you see the check mark, you can easily and immediately recognize it as being "Nike." It's not necessary to print the title to understand what they represent. Once you have built the brand, it will be long-lasting. These images convey the "brand" you know and recognize. Your brand is exclusive for your clinic and practice. With that I say and dare my colleagues that it's not how or what is your favorite color or a photo of yourself, or a picture of the impacted tooth, but rather, your brand should be something which clearly conveys a professional image that reflects what you wanted to be. It's as important as you would want this to be the cornerstone of the effective and overall strategy.

Website: Got no website? Let us not talk anymore!!! But wait, there are also several options. Using your Social Media account will be a good fit to start - just to start. It will still and always depend on your dental marketing vision, mission, taglines, and segmented target.

For your information, seventy percent $(70 \%)$ of patients look to book their dental appointments online, using a computer and mostly their mobile phones. In the Philippines alone, an individual spends five (5) hours each day (in fact we ranked No. 1 on this category) on their mobile phones on the average. That is why we must have all of these platforms of connections. This is where patients look first to buy items and services and dentistry is no exception.

Segment Your Market: Who is your target? Who would you like to become your market? For example, do you want to be the best orthodontist in the country? Or the best prostho practitioner in your city? Or maybe the best surgeon you can ever be?

Wish and desire alone won't get you there. You can't just wait and start putting work ON your practice-skills. You must work IN your clinic-business that delivers patients for your door. Makes sense? Yes, because if you do not deliver patients to your doorsteps you actually don't have anything to work ON [3].

Advertise/Promote in Multiple Platforms: If you are aware of your target market in the first place, you can now extend your marketing time targeting only that segment. You can now utilize all your expenditures in connecting with your segmented market [4].

10-15 years ago we are only limited to what we call "tri-media" which is actually TV-Television, Newspaper-Print, Radio Stations. Now, these forms of Advertising are not any more favorable if you want to reach the un-tap targeted segment of your market. There are so many available platforms to choose from such as Google ads, social media like facebook, Instagram, linkedin, pinterest, twitter, youtube channels, and many more, plus the value of having an "Artificial Intelligence". You can always take advantage of the best advertising mixes available.

Dental Marketing is a process not a single action: Like closing a dental patient for the treatment is not like telling them to do this is it, NOPE, it won't work just like marketing. Dental marketing is really a team effort and all of the efforts of each team members must be aligned with what you wanted to be. It starts with analyzing each position inside your practice and along with your staff, evaluating their role within the overall practice-marketing process.
I'll tell you this. The dentist should know who to do. When it comes to marketing all of the stakeholders including guard if you have one, may play a role in marketing.

The main goal for dental marketing or advertising is that patients and prospects book an appointment - which is usually done by picking up the phone and calling the office, tap-on-fingers. There are new ways to do more marketing today than yesterday.

\section{Definition of Terms}

» Marketing - is a process of satisfying customers' needs and wants. Allow me again to change it a bit. I will have to add profitably and Expectations. The new definition is: Marketing is a process of "profitably" satisfying customers' needs and wants plus their "expectations"

\section{» PDA-Philippine Dental Association}

» Segmentation-Market segmentation is the activity of dividing a broad consumer or business market, normally consisting of existing and potential customers, into sub-groups of consumers based on some type of shared characteristics.

» Platform-Media delivery software to connect; a framework on which applications may be run.

» Tap-on-fingers-Tap on fingers is the technology that is used to connect with friends, applications, and social media, look for dentists, and many more. Allowing them to return quickly to the surface.

» Click-to-call-also known as click-to-talk, click-to-dial, click-tochat and click-to-text, namely Web call is a form of Web-based communication in which a person clicks an object to request an immediate connection with another person in real-time either by phone call, Voice-over-Internet- Protocol, or text.

» Automation-Automatic control is the use of various control systems specifically answering calls, responses, and inquiries that reduce or eliminate human intervention.

"Chatbot-A-chatbot is a computer program or an (AI) artificial intelligence that conducts a conversation via auditory or textual methods. Such programs are often designed to convincingly simulate how a human would behave as a conversational partner. An essential tool in your Dental Marketing campaign.

»Class A-Potential High Paying Patients (Locally and Globally).

» Class B-Middle Hierarchy that may or can pay a good amount of treatment.

»Class C-Standard OP and extraction are the 2 most common treatments that this class can afford.

»Conversion-Process of closing in dentistry prospective customers who take a specific action or take the treatment. The percentage of website visitors, chatbot directed to your sites or social media accounts who fill out a form, call your company, visited your office or purchase something from you or services.

»Sole Proprietorship-A business that legally has no separate existence from its owner. The sole proprietorship is the simplest business form under which one can operate a business. The sole proprietorship is not a legal entity. It simply refers to a person who owns the business and is personally responsible for its debts.

"Corporation-A legal entity that is separate and distinct from its owners. Corporations enjoy most of the rights and responsibilities 
that an individual possesses: enter contracts, loan and borrow money, sue and be sued, hire employees, own assets and pay taxes.

» Partnership-A legal form of business operation between two or more individuals who share management and profits. In a general partnership, the partners manage the company and assume responsibility for the partnership's debts and other obligations.

\section{Objectives}

\section{General Objective}

The general objective of this dental marketing research is to identify the role of dental marketing mainframe, platform and another medium in the target of having capable paying patients.

Target Segmentation is essential in determining which way to go. Classes such as A - B - C, must be determined if you want a higher success rate in arranging your income business brackets.

\section{Specific Objective}

The specific objective of this dental marketing research is to calculate the amount a business-clinic and practitioner is willing to spend to have a targeted P 500, 000, 00 or more monthly paying patients and how many clinic-business owners are interested to do lots of dental marketing.

\section{Subjects}

\section{$1^{\text {st }}$ Phase}

Dental Clinic owners were subjected to 2 sets of questions. We have enrolled 150 dentists who own/practice in the area of NCR-National Capital Region (Manila, Philippines).

\section{$2^{\text {nd }}$ Phase}

120 dentists who own/practice in the area of NCR-National Capital Region (Manila, Philippines) were subjected to a followup interview with a 2 different set of questionnaire to answer.

\section{Methodology}

The process of identification was distinctively assigned to investigators Team.

I. Identification of Clinic location

II. Identification of Clinic Proprietor/Director/President

III. Submission of authority to Principal Investigator

IV. Clinic visit and sit down an appointment (see 5. Subjects)

\section{Results}

\section{Demographic Data}

1)

First Survey Results: Phase 1 - Trials (150 DMD) (Table 1, Graph

\section{Questions \# 1}

Clients from out of 150 DMD that were asked

- $92 \%$ or 138 of 150 dentists said they DONT have marketing subjects.

- Only $8 \%$ or 12 dentists said, yes they have marketing subjects.

Questions \#2

Clients from out of 150 DMD that were asked

- $2.0 \%$ or 3 of 150 dentists said that they have attended seminars/ lectures and read books about dental marketing.

- $98 \%$ or 147 of 150 dentists said they have NOT attended seminars/lectures and read books about dental marketing.

\section{Questions \#3}

Clients from out of 150 DMD that were asked

- Referrals from old patients $66 \%(99 \mathrm{DMD})$

- Family \& Friends $22.60 \%$ (34 DMD)

- Social Media/Website 6.1\% (9 DMD)

- Local Marketing/Community 5.3\% (2 DMD)

\section{Questions \#4}

Clients from out of 150 DMD that were asked

- $92 \%$ or 138 of 150 dentists said that they need marketing for their dental clinic.

- $8 \%$ or 12 of 150 dentists said that they DON'T need marketing for their dental clinic.

\section{Questions \#5}

Clients from out of 150 DMD that were asked

- P10k/month or less - 105 DMD - 70\%

- $\mathrm{P} 20 \mathrm{k}$ - P30k/month - 35 DMD - 23.33\%

- P40k - P50k/month - 10 DMD - 7\%

- P100k/month - 0 DMD - 0\%

Second Survey Results: Phase II-Trials (120 DMD) (Table 2, Graph 2)

\section{Questions \# 1}

They did not answer this based on the advice of the researcher/not included in the 2 nd phase of the questionnaire.

\section{Questions \#2}

They did not answer this based on the advice of the researcher/not included in the 2 nd phase of the questionnaire.

\section{Questions \#3}

Clients from out of 120 DMD that were asked

- Referrals from old patients $\quad 55.83 \%$ (67 DMD)

- Family \& Friends $18.33 \%$ (22 DMD)

- Social Media/Website 15.30\% (19 DMD)

- Local Marketing/Community 10\% (10 DMD)

\section{Questions \#4}

Clients from out of 120 DMD that were asked

- $93.33 \%$ or 112 of 120 dentists said that they need marketing for their dental clinic.

- $6.67 \%$ or 8 of 120 dentists said that they DON'T need marketing for their dental clinic.

\section{Questions \#5}

Clients from out of 120 DMD that were asked

- P10k/month or less - 72 DMD - $60 \%$

- $\mathrm{P} 20 \mathrm{k}$ - P30k/month - $30 \mathrm{DMD}$ - 25\% 
- P40k - P50k/month - 18 DMD - 15\%

- P100k/month - 0 DMD - 0\%

\section{Discussions}

Many dental and dental clinics/practitioners struggle to attract the right patients to/for their practice. Based on my FGD patient walking through their doors are not be the right age or does not require the treatments they offer which leave them having to defer, re-plan or sometimes refer patients to other dental offices or practitioners [5].

I asked most dentists about dental school and 100\% they usually tell me that they are ready to take on the dental profession but that they quickly discovered their degree didn't prepare them to run a dental practice, because there are no business subjects in their schooling. Sound familiar?

Many dentists often find themselves in this situation because dental schools don't teach much at all about the business side of dentistry. Their priority is to create clinicians, (which is important) not CEOs. BUT, your current role as a dentist \& business owner requires CEO thinking to ensure practice success.

\#1 Patients are not just purely teeth. (They are the life and blood of your business and your practice. Patients have opinions, perceptions, and expectations that all dentists must meet.

\#2 Training staff is essential and not just a day or two. The training for the staff needs an avenue for growth and development if you don't train and they will be stagnant and your business too. Providing your team with the right training and motivation positions your practice for success.

\#3 All kind of businesses needs a Leader, President or CEO, and that's neither your staff nor secretary BUT you! Meaning for you to have a business clinic success practicing dentistry is not enough; you must oversee all practice and business operations too.

Attending lots of Dental Marketing and some FGD - Focus Group Discussions will help you master the business and run it like a CEO.

Dental Marketing and Dental Advertising: They're simply not the same. If you're focusing solely on dental advertising, you are missing out on a host of opportunities. The terms marketing and advertising often get used interchangeably, but in practice, they are hardly related [6-8].

\section{Conclusion}

Dental Marketing is needed in the local settings and encourages participation from the dental practice circle. Dental Marketing provides an In-and-Out Approach to building and expanding dental practice.

$92 \%$ of respondents said they need Marketing to build their practice and thought of it as an essential tool in their business. 9.2\% increase on the use of Digital Dental Marketing platform, and an 8\% increase on a $\$ 1000$ (P50k) expenditures per month. Dental Marketing is and will always be part of the dental industry. In six (6) month time of the campaign, dental marketing has reflected good results in terms of an increase in patients turn-out.

I firmly believe that dental practice and dental business in the country is on the right tract based on the global standard for the following reasons:

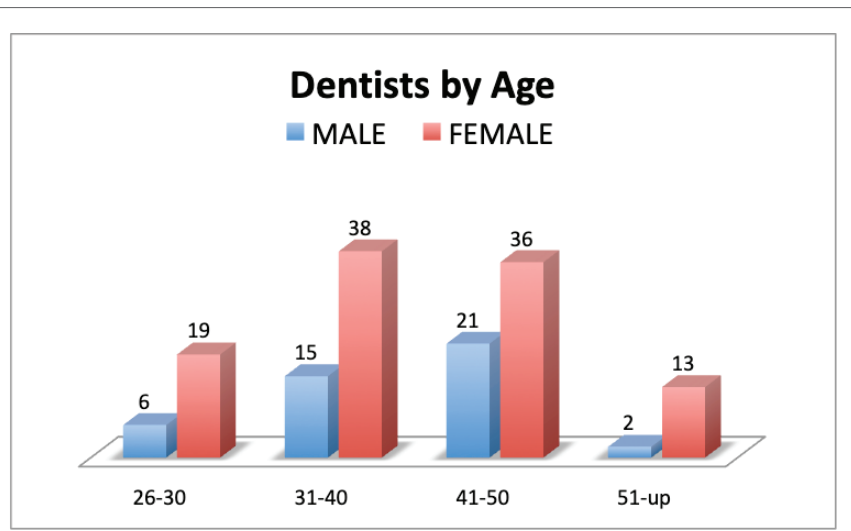

Graph 1: Phase I-150 DMD-Dentists by age.

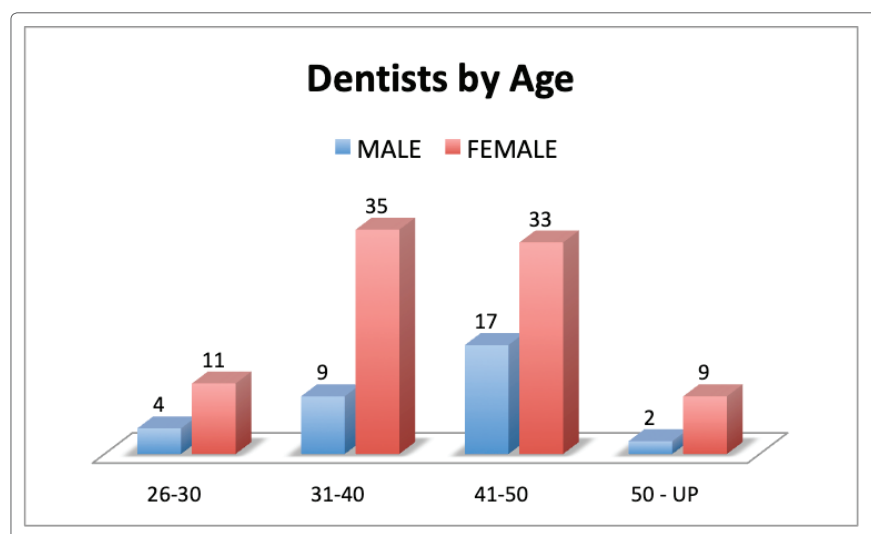

Graph 2: Phase II-120 DMD-Dentists by age.

Table 1: Phase I-150 DMD.

\begin{tabular}{|c|c|c|}
\hline Age & Male & Female \\
\hline$(26-30)$ & 6 & 19 \\
\hline$(31-40)$ & 15 & 38 \\
\hline$(41-50)$ & 21 & 36 \\
\hline$(51-$ older $)$ & 2 & 13 \\
\hline Total & 44 & 106 \\
\hline
\end{tabular}

*All are clinic owners

Table 2: Phase II-120 DMD.

\begin{tabular}{|c|c|c|}
\hline Age & Male & Female \\
\hline$(26-30)$ & 4 & 11 \\
\hline$(31-40)$ & 9 & 35 \\
\hline$(41-50)$ & 17 & 33 \\
\hline$(51-$ older $)$ & 2 & 9 \\
\hline Total & 32 & 88 \\
\hline
\end{tabular}

*All are clinic owners 
- Price Point

- Dentists skill Set

- Maturing market (patients)

Other points: Do not only talk marketing, but also incorporate specific marketing responsibilities into staff job explanations and evaluate individuals throughout performance reviews while you use other responsibilities. Most significantly, if staff people have a problem with their marketing roles, seek training and assistance. Their confidence and success is crucial for your "campaign" as well as your capability to achieve your marketing goals within the lengthy-term.

Finally, don't travel the marketing route alone. This essential practice system, when correctly funded and supported, will yield true lengthy-term success. To effectively execute all these basic principles plus an overall effective online marketing strategy requires some time and the guidance of the dental-practice marketing professional who isn't inside it only to sell you a fast fix and leave.

\section{Author's Recommendations}

I would love to have more of the following:

- Large Scale Marketing Survey of more than 500 dentists as subjects

- More marketing lectures and seminars for dental practitioners.

- Training of all Medical/Allied services in dental practice.

\section{Limitations}

The author did not cover the region of Bicol and another town in the provinces of Central Luzon, North Luzon, Visayas, and Mindanao.

\section{Dental Marketing Products Offers}

»Website-Itshouldbearesponsivewebsite

» SEO-Optimization

» Profile Reputation Management-SM/Website

»PPC-Pay Per Click

》Social Media Marketing \& Management

» Manage Practice Listings

»Call Tracking

》Video/Blogging

»Re-targeting

» Patient Recall- Email and Phone Call

»Logo

»Analytic Indicators

»AI-Chatbot

» Patient Management Program

»Clinical/Expense/Inventory Report

\section{Actual Dental Marketing Question Form}

2 sets of questions with 5 key points and an interval of 6 months per dentists.

\section{Primary Questions:}

Form of Business/Clinic:
_Sole Proprietorship

_Partnership

Corporation

Interested to participate?_YES _NO (if no, return the form to the agents)

Questions:

1. Do you have marketing subjects during your college years in dentistry?

YES__ NO

2. During your practice years, have you regularly read books, attended seminars/lectures on dental marketing? YES $\mathrm{NO}$

3. As Dentists, where do you get clients/patients?

a.___ Referrals from old patients

b. ___ Family \& Friends

c. ___ Social Media/Website

d. ___Local Marketing/Community

4. Do you believe that for you to build your practice, you need dental marketing?

_ Y YES _ _ NO

5. How much money do you intent to spend in order to have to pay patients and earnings of P500,000.00 / month?

$\mathrm{P} 10 \mathrm{k} / \mathrm{month}$ or less

P20k - P30k/month

$\mathrm{P} 40 \mathrm{k}-\mathrm{P} 50 \mathrm{k} / \mathrm{month}$

P100k/month

\section{References}

1. Dental Marketing Philippines.

2. Random report from *PDA-Philippine Dental Association last 20082010.

3. Practice management.

4. Roche P Ruiz, MBA Marketing YouTube channel.

5. Rinesh Ganatra (2013) Re-Inventing Dentistry: A New Vision for Building and Marketing Your Dental Practice.

6. Josh Weltman (2015) Seducing Strangers: How to get people to buy what you're selling.

7. Roche P Ruiz-I Met A Stupid Dentists: Dental Marketing Book.

8. Kevin Mirasol-Pro Dental Marketing. 